


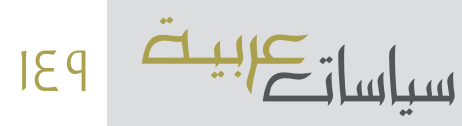

$$
\begin{aligned}
& \text { أهم محطات التحوّل الديمقراطي } \\
& \text { في الوطن العربي }
\end{aligned}
$$

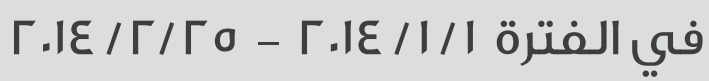


شمل ذلك ممثلي المؤتمر الشعبي العام وأحزاب التحالف الوطني الديمقراطي وحزب اتحاد الرشاد وباقي منظمات المجتي المتمع المدني.

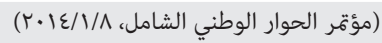

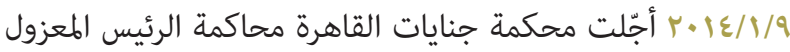

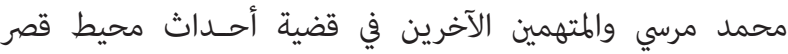

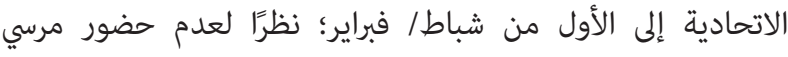
الجلسة بسبب عدم قكّن أمن القاهرة من إحضاره من سجن برج العرب بالإسكندرية بسبب سوء الأحوال الجوية.

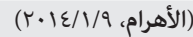

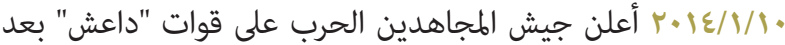
شنها هجمات على محافظات عدة في شمال سورية، وشهدت حريتان وجرابلس بريف حلب ودير الزور هجمات من قبل داعش، بينما دارت اشتباكات عنيفة في أرياف حلب والرقة بين داعش و"مقاتلي المعارضة".

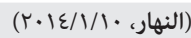

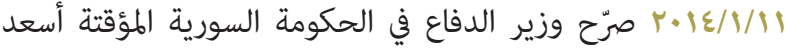
مصطفى أنّ الوازرة تجري مناقشات مع مختلف القوى العسكرية،

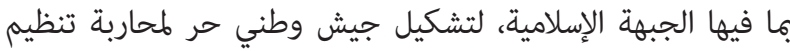

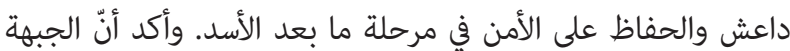
تدرس مسألة انضمامها، بينما أبدت الكتائب الأخرى رغبتها في الانضمام للجيش الوطني. وقال بأنه سيجري توحيد جميع الكتائب في إطار إندار

تأسيس جيش وطني لا يتدخل في السياسة، ومهمته حماية الوطن.

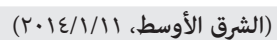

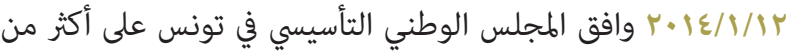
نصف مشروع الدستور، وبلغت الجلسة الفصل ال من باب السلطة التنفيذية. وتم إسقاط الفصل سٓ المحدِّد لشروط الترشح لرئاسة

الجمهورية وذلك لعدم موافقة اللجنة بشأن الجنسية والسن.

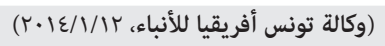

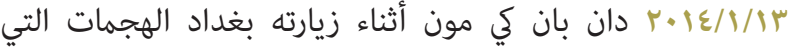
استهدفت المدنيين في العراق، ودعا جميع القادة السياسيين العراقيين

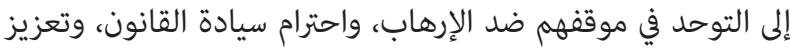
النسيج الاجتماعي والحوار الذي يشمل الجميع، من خلإِ ملال المشاركة السياسية والمؤسسات الديمقراطية.

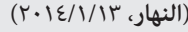

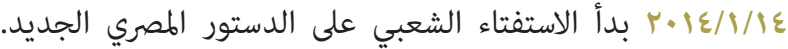

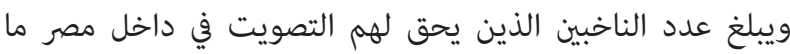
يقارب or مليون ناخب، موزعين على •بّ ألف مركز اقتراع.

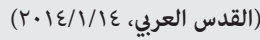

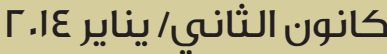

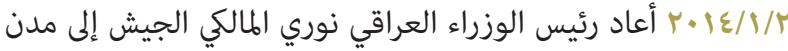
محافظة الأنبار استجابة لنداء محافظها بعدما سيطر مسلحون على الى 17 مركزًا للشرطة وبعد تهريب نحو مئة سجين في الرمادي والفلوجة. وتعهَّد المالكي بإرسال قوات إضافية من الجيش وملاحقة الميليشيات والجماعات الإرهابية في الأنبار وإنقاذ أهلها من تنظيم الدولة الإسلامية في العراق والشام "داعش".

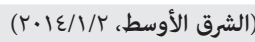

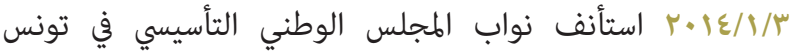
نقاش الدستور فصلًا فصلًا في إطار الجلسة العامة لناقشة الدستي الدستور. وبحضور 197 نائبًا، قت مناقشة مضامين الدستور من عناوين

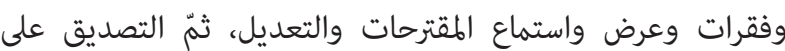
الصيغة النهائية المعدّلة. وبدأ النقاش حول تسمية مشروع دستور الجمهورية التونسية، وصوّت VO النبيًا للاحتفاظ بالتسمية.

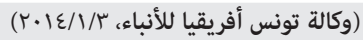

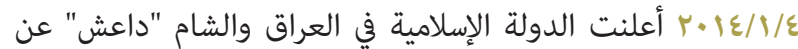
تبنيها التفجير الذي استهدف معقل حزب الله في الضاحية الجنوبية

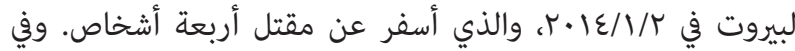

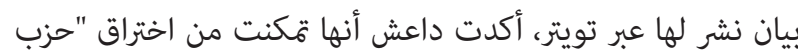
الشيطان"، وأنّ هذا التفجير هو دفعة أولى، وأشارت إلى أنّ هناك اكت آنات

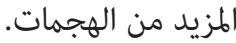

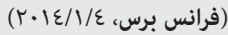

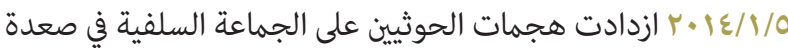
والجوف في اليمن، وذلك بالتزامن مع نهاية الحوار الوطني اليمني واستكمال مناقشة تقرير فريق العدالة الانتقالية. وأكد التقرير التزام

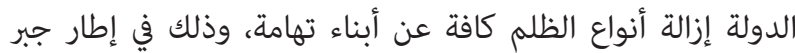
الضرر الاجتماعي وإدراجهم في خطط التنمية الاقتصادية والاجتماعية التهاء التهاء والتعليمية وبرامجها ومَا يحقق شراكتهم في السلطة والثروة.

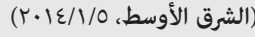

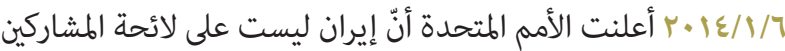

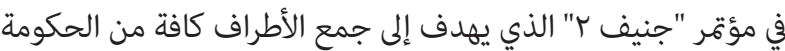
السورية والمعارضة على طاولة التفاوض، وذلك من أجل إنهاء العنف والنزاع القائم وضمان عملية انتقال سياسي سلمي عبر تنفيذ بيان

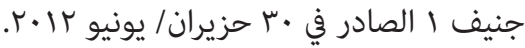

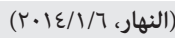

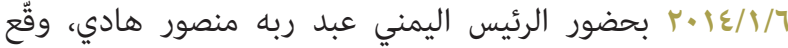

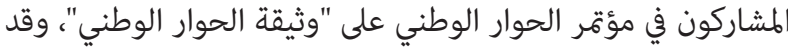




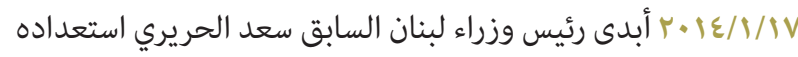
للمشاركة في حكومة ائتلافية جديدة مع جماعة حزب إبي الله، باعتبارها

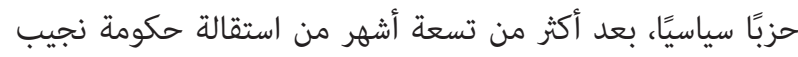

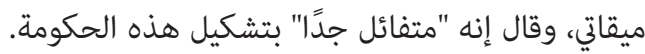

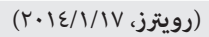

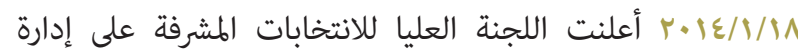

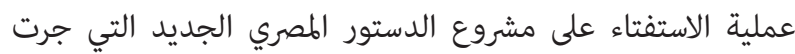

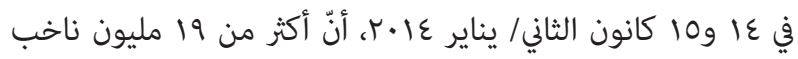

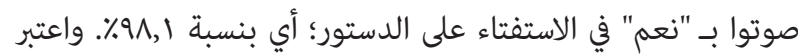

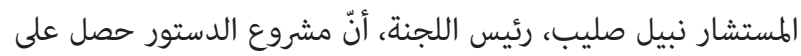

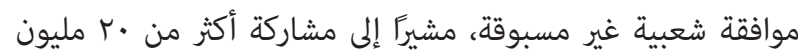

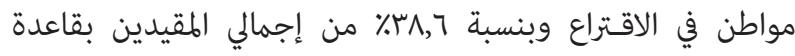

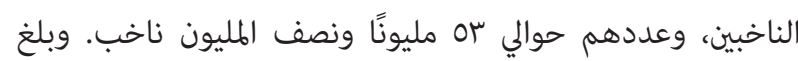

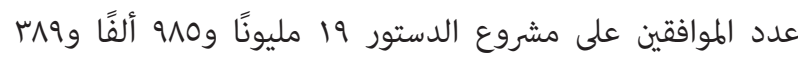

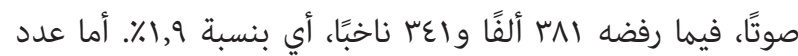

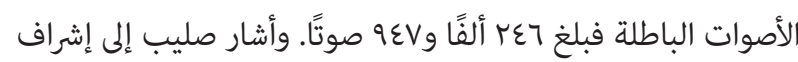

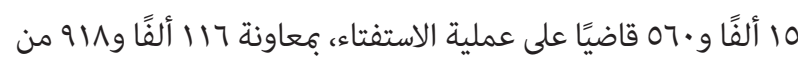

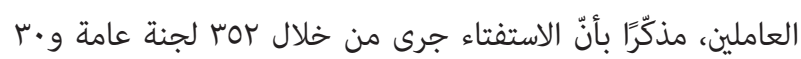
ألفًا وVاس لجنة فرعية وراعا لجنة للوافدين.

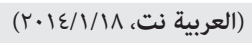

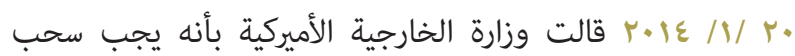

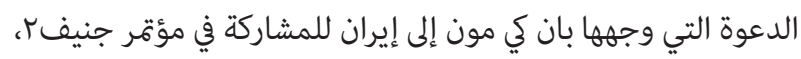

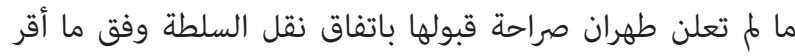

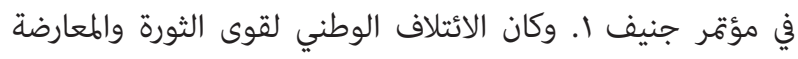

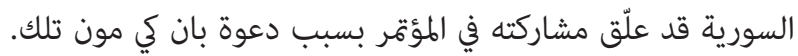
وقال عضو الهيئة السياسية في الائتلاف أنس العبدة إنّ الأمين العام

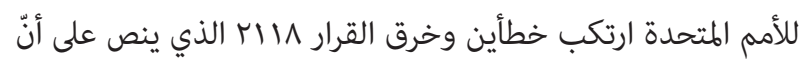

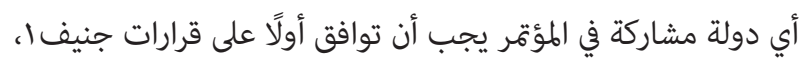

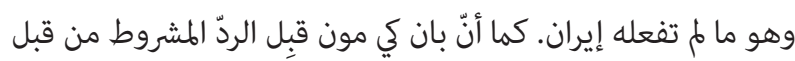

$$
\text { النظام السوري لحضور جنيف r. }
$$

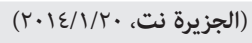

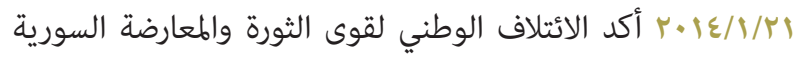

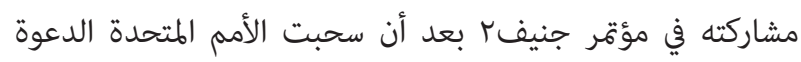

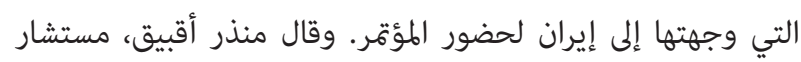
الشؤون الرئاسية في الائتلاف، إنّ الائتلاف يقدِّر للأمم المتحدة وأمنينها

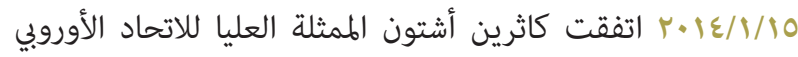

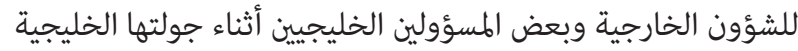

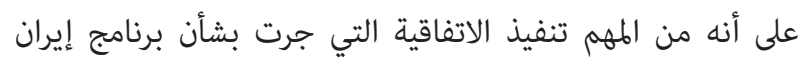
النووي بين دول 0+1 وطهران. وأضافت أنّ تنفيذ الاتفاقية سيدفع إنفان

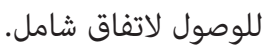

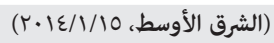

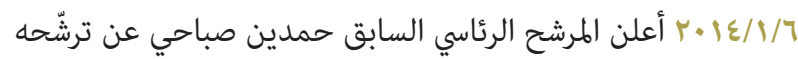

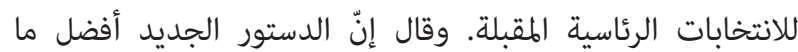
حصلت عليه مصر، ودعا إلى التصويت عليه بـ "نعم".

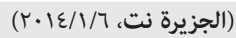

r r.1/1/10 أقرّت لجنة التوفيق بمؤتمر الحوار الوطني اليمني

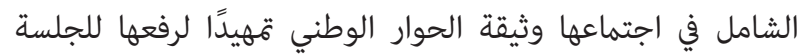

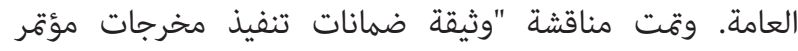

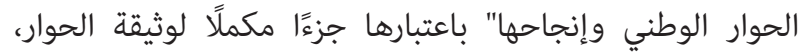

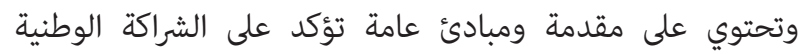

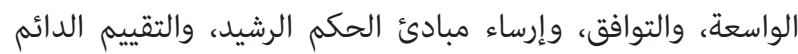

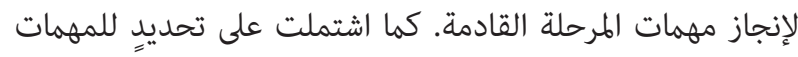

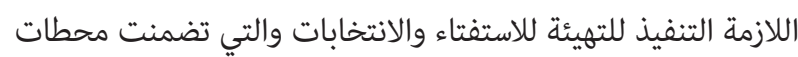

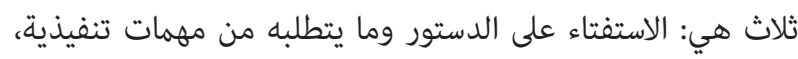

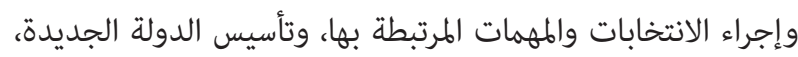

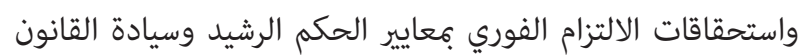

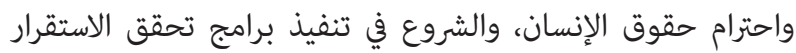

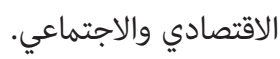

(مؤتمر الحوار الوطني الشامل، (r/10/10)

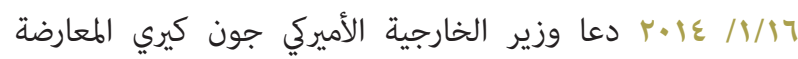

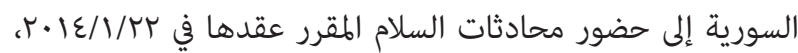

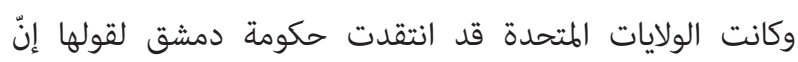
الاجتماع يجب أن يتناول مكافحة الإرهاب وليس العمل لإيجاد النقاد

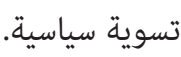

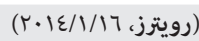

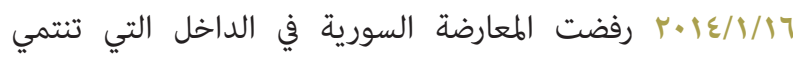

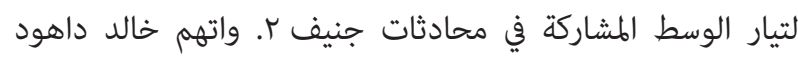

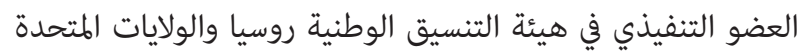
باستعجال عقد المؤتمر من أجل مصالحهما في المنطقة وليس من ألجئ ألجل

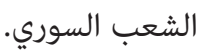

\section{( (}


خمدينتي الفلوجة والرمادي في محافظة الأنبار منهم 70 ألفًا نزحوا

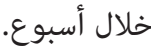

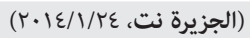

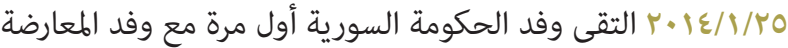
خلال اجتماع مباشر في محادثات السلام التي تجري بينهما في جنيف.

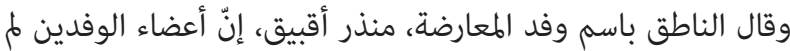
يتحدثا في ما بينهما، وإفا اكتفيا بالاستماع إلى عرض رئيس الجلسة، مبعوث جامعة الدول العربية والأمم المتحدة، الأخضر الإبراهيمي.

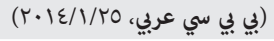

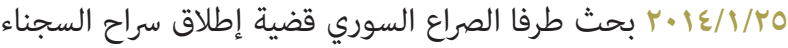

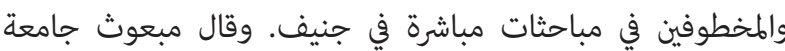

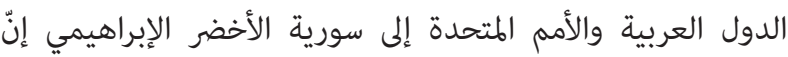

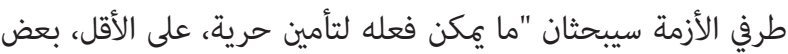

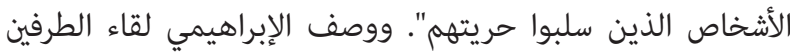

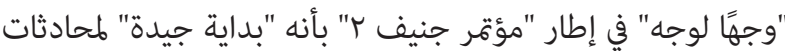
السلام الرامية إلى بحث مخرج للصراع السوري. وأوضح أنّ القضايا محل النقاش تمثل بداية لتناول قضية تشكيل حكومة انتقالية في سورية. وكانت مفاوضات الطرفين في عץ كانون الثاني/ يناير قد ركزت على بحث سبل توفير طرق آمنة لنقل مساعدات إنسانية إلى المناطق

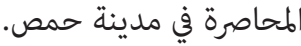

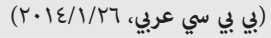

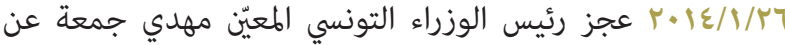
تقديم تشكيلة حكومته في المهلة التي منحها له رئيس البلاد منصف

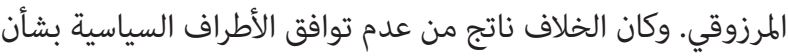

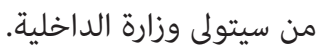

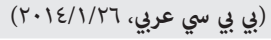

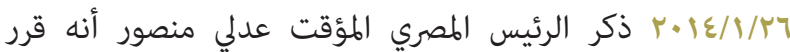
تعديل "خريطة المستقبل" المتعلقة بالمسار السياسي في البلاد بعد عزل الرئيس محمد مرسي، مقدمًا الانتخابات الرئاسية على البرمانية.

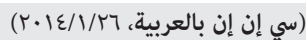

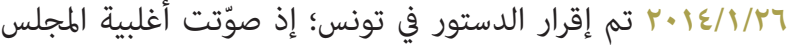
الوطني التأسيسي (البرلان) على مشروع الدستور الجديد من القراءة الأولى، وذلك بعد ساعات من إعلان رئيس الوزراء المكلف مهدي جمعة تشكيل حكومته الانتقالية الجديدة وفق آليات الحوار الوطني عقب تخطي الخلاف بشأن حقيبة وزارة الداخلية. وقد صوّت لمصلحة
العام بان كي مون فهمهما لموقف الائتلاف ويعتقد أنهما اتخذا القرار الصحيح وأنّ مشاركة الائتلاف مؤكدة.

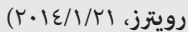

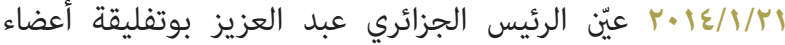
اللجنة الوطنية للإشراف على الانتخابات الرئاسية المقررة في نيسان/ أبريل عا.ب، والتي ستتولى مراقبة المسار الانتخابي بدءًا من إيداع الترشيحات وحتى انتهاء الاقتراع وإعلان النتائج من قبل المجلس الدستوري مع توفير الظروف لضمان شفافية الانتخابات ونزاهتها. (الجزيرة نت، (r/I//T)

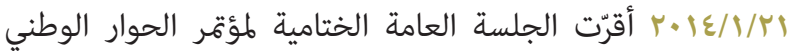

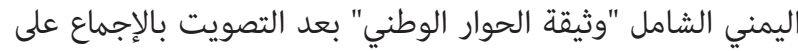

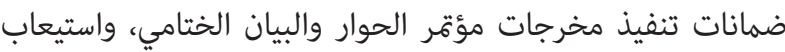

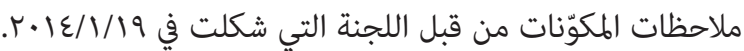

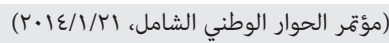

اب / / / / ب أقرّ الرئيس اليمني عبد ربه منصور هادي، الوثيقة النهائية للحوار الوطني في البلاد، على الرغم من اغتيال رئيس فريق الحوثيين المشارك في الحوار أحمد شرف الدين، وإعلان الحوثيين

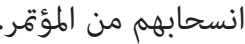

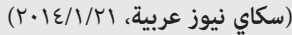

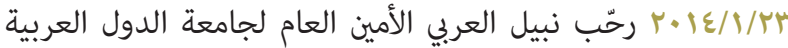
بنجاح مؤتمر الحوار الوطني في اليمن وإقرار "وثيقة الحوار الوطني"،

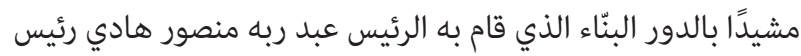

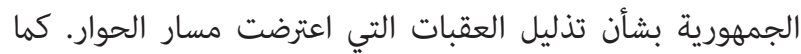

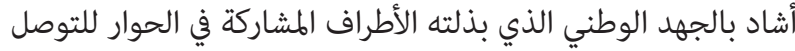

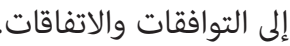

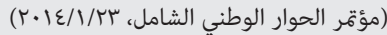

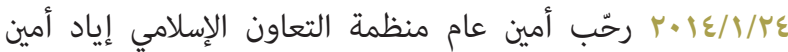

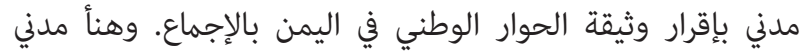
الحكومة اليمنية والشعب اليمني على هذا الإنجاز التاريخي، مؤكدًا دعم منظمة التعاون الإسلامي مخرجات الحوار الوطني التي تؤسس لمستقبل واعد لليمن الجديد ينعم فيه شعبه بالأمن والاستقرار

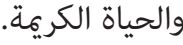

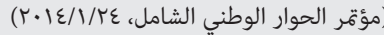

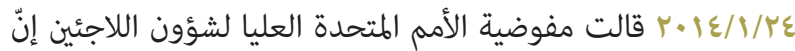
أكثر من •عا ألف عراقي قد شُرِّوا من بيوتهم بسبب المعارك الدائرة 
لعهدة رابعة في الانتخابات الرئاسية المقررة في IV نيسان/ أبريل المقبل. وأمام الرئيس الجزائري مهلة حتى التئابت ارتيه 10 آذار/ مارس للإعلان

عن الترشح من عدمه.

\section{( فرانس ع r، (r) (}

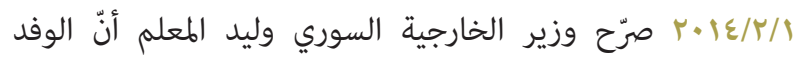

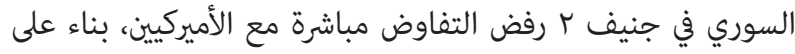

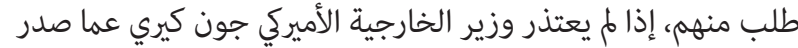
عنه بشأن بشار الأسد في افتتاح المؤةر بمدينة مونترو السويسرية.

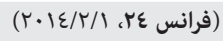

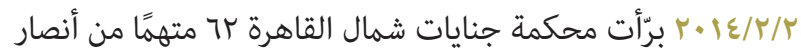

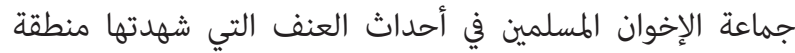

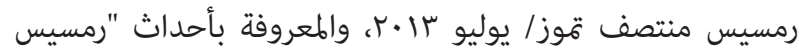
الأولى"، من "ارتكاب أعمال عنف وبلطجة وإثارة شغب".

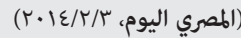

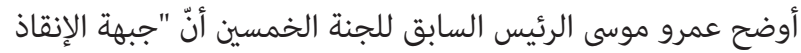

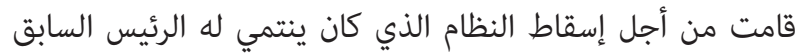

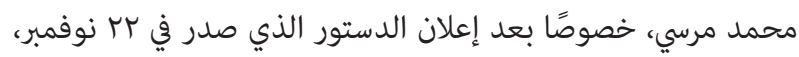

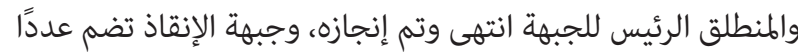

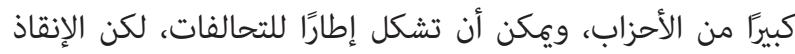

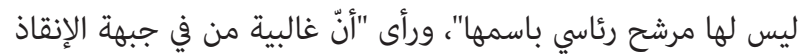
يدعمون السيسي". وقال إنّ طرح بعض المقترحات بات بأن يرشح السيسي

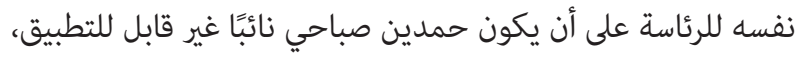
"لأن الدستور مل يقر بوجود نائب للرئيس".

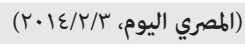

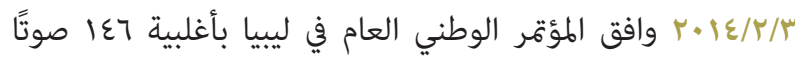
على خريطة طريق جديدة تنص على تعديل الإعلان الدستوري، وإيجاد بديل من رئيس الحكومة المؤقتة علي زيدان في فترة لا تتجاوز

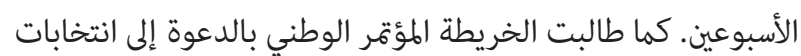

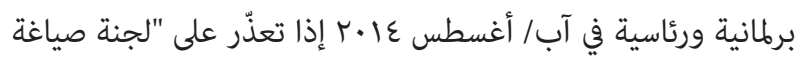

الدستور" إقام مهماتها في المدة المقررة لها.

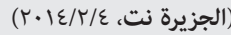

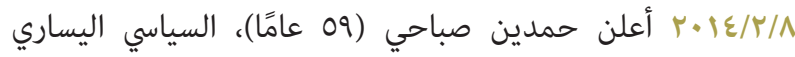

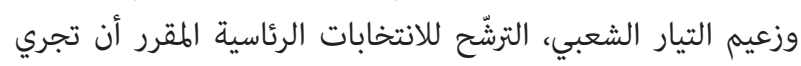
هذا العام في مصر.

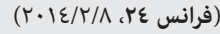

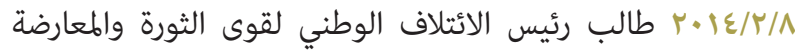

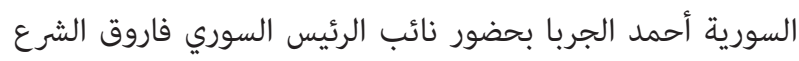

الدستور ... نائب، مقابل r ا نائبًا صوتوا ضده، وامتنع أربعة نواب

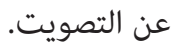

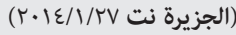

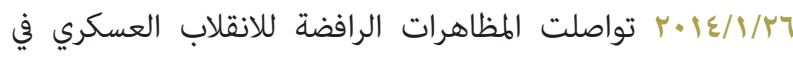

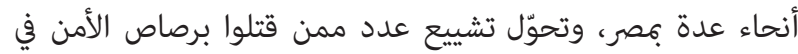
الذكرى الثالثة لثورة ro يناير إلى مظاهرات طالبت بالقداء لقداص لدماء

هؤلاء وإنهاء حكم العسكر.

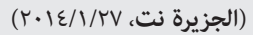

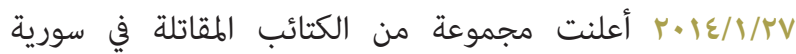
اندماجها وتأسيس حركة جديدة أطلق عليها اسم "حزم".

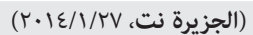

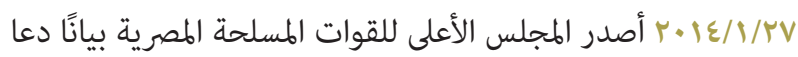
فيه "عبد الفتاح السيسي أن يتصرف وفق ضميره الوطني ويتحمّل الفيل

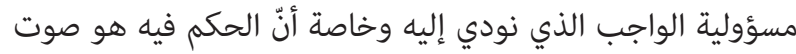

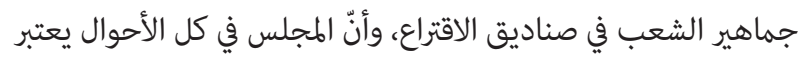

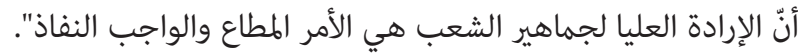

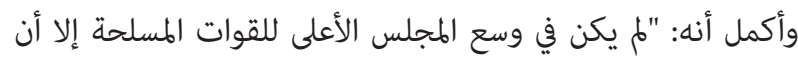

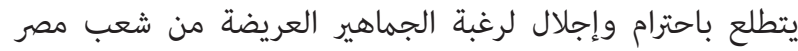

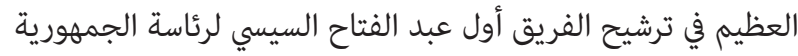
وهى تعتبره تكليفًا والتزامًا".

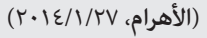

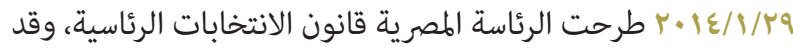

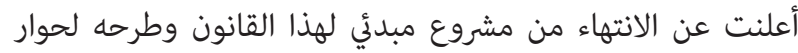

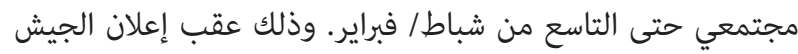

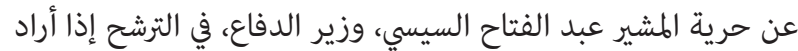
ذلك "نزولًا على رغبة الشعب".

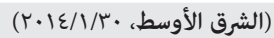

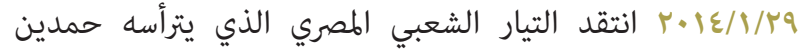

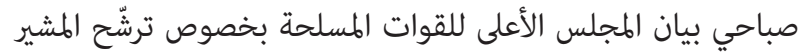

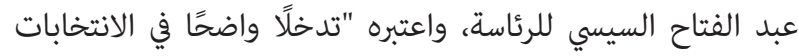

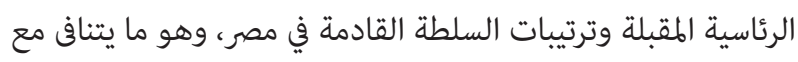
الدستور والأعراف الديمقراطية والتقاليد السياسية التي يجب على لئلى

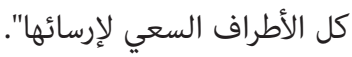

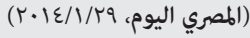

\section{شباط / فبراير}

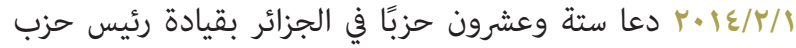
"تاج"، وزير النقل عثّار الغول، الرئيس عبد العزيز بوتفليقة إلى الترشح 